\title{
$\mathrm{ZnO}$ 와 Al-doped ZnO 박막의 표면 형상과 전기·광학적 특성에 미치는 Wet Etching 시간의 영향
}

\author{
김민성 ${ }^{1, a}$ \\ ${ }^{1}$ 동명대학교 정보통신공학과
}

\section{The Effect of Wet Etching Time on the Surface Roughness and Electrical and Optical Properties of $\mathrm{ZnO}$, and $\mathrm{Al}$-doped $\mathrm{ZnO}$ Films}

\author{
Min-Sung Kim ${ }^{1, a}$ \\ ${ }^{1}$ Department of Information \& Communications Engineering, TongMyong University, Busan 608-711, Korea
}

(Received January 21, 2013; Revised January 23, 2013; Accepted February 4, 2013)

\begin{abstract}
We investigated the effect of etching time on the surface roughness, and electrical and optical properties of $\mathrm{ZnO}$ and $2 \mathrm{wt} \% \mathrm{Al}$-doped $\mathrm{ZnO}$ (AZO) films. The $\mathrm{ZnO}$ and $\mathrm{AZO}$ films were deposited on glass substrates by $\mathrm{RF}$ magnetron sputtering technique. The etching experiment was carried out using a solution of $5 \% \mathrm{HCl}$ at room temperature. The surface roughness was characterized by Atomic Force Microscopy. The electrical property was measured by Hall measurement system and 4-point probe. The optical property was characterized by UV-vis spectroscopy. After the wet chemical etching, the surface textures were obtained on the surface of the $\mathrm{ZnO}$ and $\mathrm{AZO}$ films. With the increase of etching time, the surface roughness (RMS) of the films increased and the transmittance of the films was observed to decrease. For the AZO film, a low resistivity of $1.0 \times 10^{-3} \Omega \cdot \mathrm{cm}$ was achieved even after the etching.
\end{abstract}

Keywords: $\mathrm{ZnO}, \mathrm{Al}$-doped $\mathrm{ZnO}$, Electrical \& optical properties, Texture structure, Wet etching time

\section{1. 서 론}

투명 전도성 산화막 (transparent conducting oxide, $\mathrm{TCO})$ 은 우수한 전기적 특성과 가시광선 영역 의 높은 투과율, 넓은 에너지 밴드갭을 갖고 있는 장 점 때문에 다양한 평판 디스플레이 (flat panel display), 태양전지의 윈도우 층 (window layer), 스마

a. Corresponding author; minsung@tu.ac.kr

Copyright (C2013 KIEEME. All rights reserved.

This is an Open-Access article distributed under the terms of the Creative Commons Attribution Non-Commercial License (http://creativecommons.org/licenses/by-nc/3.0) which permits unrestricted non-commercial use, distribution, and reproduction in any medium, provided the original work is properly cited.
트 윈도우 (smart window), 각종 센서 등 광범위한 분야에 사용됨에 따라 많은 관심을 끌고 있다 [1-3]. 많은 재료들 중 현재는 낮은 비저항 $\left(<1 \times 10^{-4} \Omega\right.$. $\mathrm{cm})$, 높은 일함수 $(>4.8 \mathrm{eV})$, 높은 투과율 $(>90 \%)$, 우수한 에칭 성능 등의 장점을 갖고 있는 $\mathrm{ITO}$ (Indium Tin Oxide) 박막이 가장 널리 이용되고 있다 [4]. 그러나 이러한 장점에도 불구하고 $\mathrm{ITO}$ 는 고온 공정 시 $\mathrm{In}$ 과 $\mathrm{Sn}$ 이 환원되는 열 - 화학적 불안정성을 갖고 있고, 화합물의 주 구성원소인 $\mathrm{In}$ 과 $\mathrm{Sn}$ 의 희귀 성으로 인해 매우 고가의 물질로 소자 제작 시 생산 단가를 높이는 주요 원인으로 작용함에 따라 대량생 산에 부적합한 것으로 평가 받고 있다 [5,6]. 위와 같 은 이유로 최근 생산 단가를 낮추고, 열 - 화학적으로 
안정성이 우수한 $\mathrm{TCO}$ 물질에 대한 연구 필요성이 대두됨에 따라 ITO를 대체할 물질에 대한 연구가 활 발히 진행되고 있다. 예를 들면 최근에 T. Hitoshigi 그룹에서 발표한 $\mathrm{Nb}$ 가 도핑된 $\mathrm{TiO}_{2}$ 의 경우, $5 \mathrm{at} \%$ 전후의 $\mathrm{Nb}$ 도핑된 $\mathrm{TiO}_{2}$ 박막의 저항률이 $3 \times 10^{-4}$ $\Omega \cdot \mathrm{cm}$ 대의 값을 보여 $\mathrm{In}$ 이 전혀 사용되지 않은 $\mathrm{TCO}$ 로서 큰 주목을 받기도 하였다 [7].

현재 ITO를 대체할 물질로 가장 각광받고 있는 것 은 $\mathrm{ZnO}$ (znic oxide)이다. $\mathrm{ZnO}$ 물질은 열 · 화학적으 로 매우 우수한 안정성과 동시에 습식 에칭이 가능하 며, 인체에 무해하고 매장량이 풍부하여 In에 비해 생 산 단가가 매우 저렴하다는 장점을 갖고 있다. 또한 박막 제조 과정에서 $\mathrm{II}$ 족 원소 $(\mathrm{Al}, \mathrm{Ga}, \mathrm{B})$ 를 도핑시 킴으로써 비저항을 낮출 수 있고, 밴드갭을 조절할 수 있는 특성도 갖고 있어 최근 관련 연구가 활발히 진행되고 있는 실정이다 [6].

한편, 박막 $\mathrm{Si}$ 태양전지의 고효율화를 실현하기 위 해 $\mathrm{TCO}$ 층의 표면을 텍스쳐 구조로 거칠게 함으로써 태양광의 내부 산란을 유도하여 광흡수 효율을 높이 는 light trapping효과를 이용하는 방법이 주목을 받 고 있다. 본 논문에서는 wet etching을 이용하여 $\mathrm{ZnO}$ 와 $\mathrm{Al}$-doped $\mathrm{ZnO}$ 박막의 표면에 텍스쳐 구조를 형성 하였을 때, etching 시간이 텍스쳐 구조와 박막의 전 기·광학적 특성에 미치는 영향을 살펴보았다.

\section{2. 실험 방법}

$\mathrm{RF}$ magnetron sputtering system을 이용하여 glass 기판에 $\mathrm{ZnO}$ 박막을 제조하였다. $\mathrm{ZnO}$ 박막의 증착에는 $\mathrm{ZnO}$ (약99.9\%) 타겟을 이용하였으며 Base pressure는 $7.0 \times 10^{-7}$ Torr, 스퍼터링 압력은 $50 \mathrm{mTorr}$ 에서 증착을 행하였다. 스퍼터링 가스로는 $\mathrm{Ar}$ 을 사용하였으며 $\mathrm{RF}$ power는 $150 \mathrm{~W}$, 기판온도는 $100^{\circ} \mathrm{C}$ 로 하였다. $\mathrm{Al}-$ doped $\mathrm{ZnO}$ 박막의 증착에는 $2 \mathrm{wt} \% \mathrm{Al}$-doped $\mathrm{ZnO}$ 타겟을 사용하였고 $7.0 \times 10^{-7}$ Torr까지 진공상태로 한 후 $\mathrm{Ar}$ gas를 주입하여 $10 \mathrm{mTorr}$ 조건에서 스퍼터링을 행하 였다. 기판온도는 $100^{\circ} \mathrm{C}, \mathrm{RF}$ power는 $100 \mathrm{~W}$ 로 하였 다. 표 1 에 증착조건을 나타내었다. Etching 실험은 실 온에서 HCI 5\% 수용액을 이용하여 진행하였다. Etching 실험 전후 hall measurement system 및 4-point probe를 통해 전기적 특성을 분석하였고, UV-VIS spectroscopy를 통해 광학적 특성을, 표면 형 상 변화를 관찰하기 위해 $\mathrm{AFM}$ 을 사용하였다.
Table 1. Experimental conditions of $\mathrm{ZnO} \& \mathrm{AZO}$ thin films.

\begin{tabular}{ccc}
\hline Parameter & Pure $\mathrm{ZnO}$ & $\mathrm{Al}$ doped $\mathrm{ZnO}$ \\
\hline \hline Target & $\mathrm{ZnO}$ & $\mathrm{AZO} 2 \mathrm{wt} \%$ \\
\hline Substrate & Glass & Glass \\
\hline $\begin{array}{c}\text { Temperature }\left({ }^{\circ} \mathrm{C}\right) \\
\text { Primary } \\
\text { pressure }(\text { torr })\end{array}$ & $700^{\circ} \mathrm{C}$ & $100^{\circ} \mathrm{C}$ \\
\hline $\begin{array}{c}\text { Sputtering } \\
\text { pressure }(\text { torr })\end{array}$ & $50 \mathrm{mTorr}$ & $7 \times 10^{-7}$ Torr \\
\hline RF-power & $150 \mathrm{~W}$ Torr \\
\hline Deposition time & $20 \sim 50 \mathrm{~min}$ & $100 \mathrm{~W}$ \\
\hline Pre sputtering & $5 \mathrm{~min}$ & $5 \mathrm{~min}$ \\
\hline
\end{tabular}

\section{3. 결과 및 고찰}

그림 1(a)는 RF-power $150 \mathrm{~W}$, 스퍼터링 압력 50 $\mathrm{mTorr}$, 기판온도 $100^{\circ} \mathrm{C}$ 조건에서 50 분간 증착한 $\mathrm{ZnO}$ 박막의 etching 시간에 따른 표면형상 변화를 보여주 는 $\mathrm{AFM}$ 이미지이고, 그림 1(b)는 etching 시간에 따 른 표면 roughness의 변화를 나타내는 그래프이다.
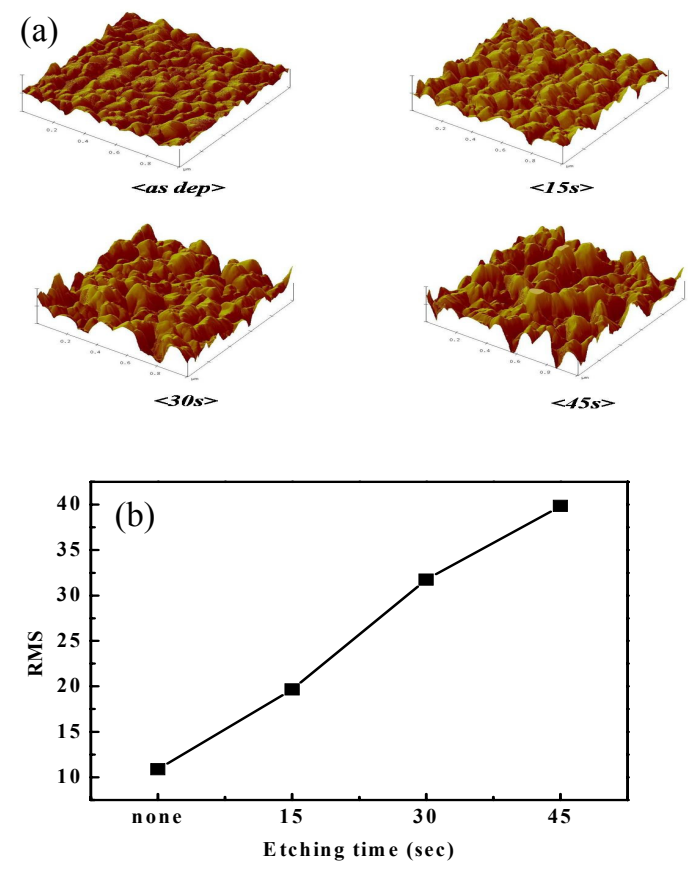

Fig. 1. Surface morphological properties of $\mathrm{ZnO}$ films on glass substrates with varying etching time: (a) AFM image, (b) RMS. 
(a)
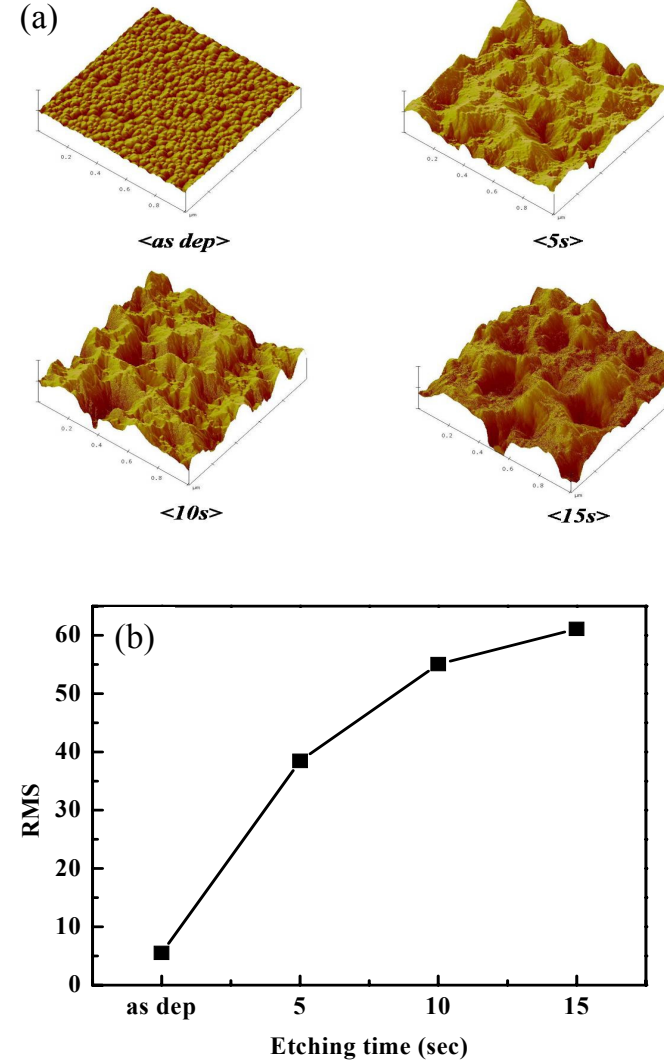

Fig. 2. Surface morphological properties of $\mathrm{ZnO}$ films on glass substrates with varying etching time: (a) AFM image, (b) RMS.

그림 2(a)는 RF-power $100 \mathrm{~W}$, 스퍼터링 압력 10 $\mathrm{mTorr}$, 기판온도 $100^{\circ} \mathrm{C}$ 의 증착조건에서 25 분간 증착 한 AZO 박막의 etching 시간에 따른 표면 형상 변화 를 보여주는 $\mathrm{AFM}$ 이미지이고, 그림 2(b)는 etching 시간에 따른 표면 roughness를 나타내는 RMS 변화 를 보여주는 그래프이다. 그림 1 과 그림 2에서 볼 수 있듯이 두 박막 모두 etching 시간이 증가하면서 표 면이 피라미드 형상을 보이며 texturing structure가 형성되었고, etching 시간이 증가함에 따라 RMS값이 증가하는 것을 관찰할 수 있었다.

그림 3(a)는 RF-power $150 \mathrm{~W}$, 스퍼터링 압력 50 $\mathrm{mTorr}$, 기판온도 $100^{\circ} \mathrm{C}$ 의 증착조건에서 50 분간 증착 한 $\mathrm{ZnO}$ 박막의 etching 시간에 따른 박막의 두께 변 화 및 비저항의 변화를 보여주는 그래프이며, 그림 3(b)는 RF-power $100 \mathrm{~W}$, 스퍼터링 압력 $10 \mathrm{mTorr}$, 기판온도 $100^{\circ} \mathrm{C}$ 의 조건에서 25 분간 증착한 $\mathrm{AZO}$ 박막
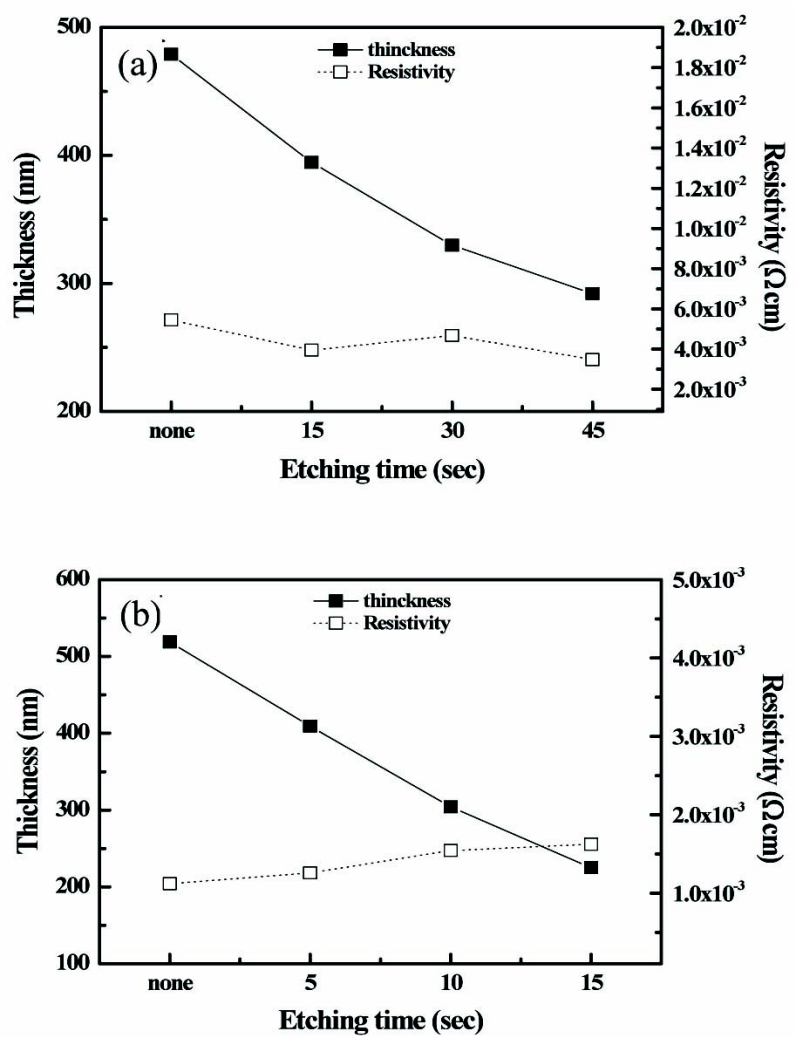

Fig. 3. Electrical properties of thin films on glass substrates with varying etching time: (a) $\mathrm{ZnO}$, (b) AZO.

의 etching 시간에 따른 두께 변화 및 비저항의 변화 를 보여주는 그래프이다.

그림 3의 그래프에서 확인할 수 있듯이 $\mathrm{ZnO}$ 의 경 우 etching 시간이 증가함에 따라 박막의 두께가 478 $\mathrm{nm}$ 에서 $292 \mathrm{~nm}$ 로 감소하였고, 비저항은 $5.4 \times 10^{-3}$ $\Omega \cdot \mathrm{cm}$ 에서 $3.4 \times 10^{-3} \Omega \cdot \mathrm{cm}$ 약간 감소하는 경향을 보였으나 평균적으로 $4.0 \times 10^{-3} \Omega \cdot \mathrm{cm}$ 의 낮은 비저항 값을 보였다. 또한 $\mathrm{AZO}$ 의 경우 etching 시간이 증가 함에 따라 박막의 두께가 $519 \mathrm{~nm}$ 에서 $225 \mathrm{~nm}$ 로 감 소하였고, 비저항은 $1.0 \times 10^{-3} \Omega \cdot \mathrm{cm}$ 의 낮은 비저항 값을 보이는 것을 확인할 수 있었다.

그림 4(a)는 $\mathrm{RF}$-power $150 \mathrm{~W}$, 스퍼터링 압력 50 $\mathrm{mTorr}$, 기판온도 $100{ }^{\circ} \mathrm{C}$ 의 조건에서 50 분간 증착한 $\mathrm{ZnO}$ 박막의 etching 시간에 따른 투과율 변화를 보 여주는 그래프이며, 그림 4(b)는 RF-power $100 \mathrm{~W}$, 스퍼터링 압력 $10 \mathrm{mTorr}$, 기판온도 $100^{\circ} \mathrm{C}$ 의 조건에 서 25분간 증착한 $\mathrm{AZO}$ 박막의 etching 시간에 따른 투과율 변화를 보여주는 그래프이다. 

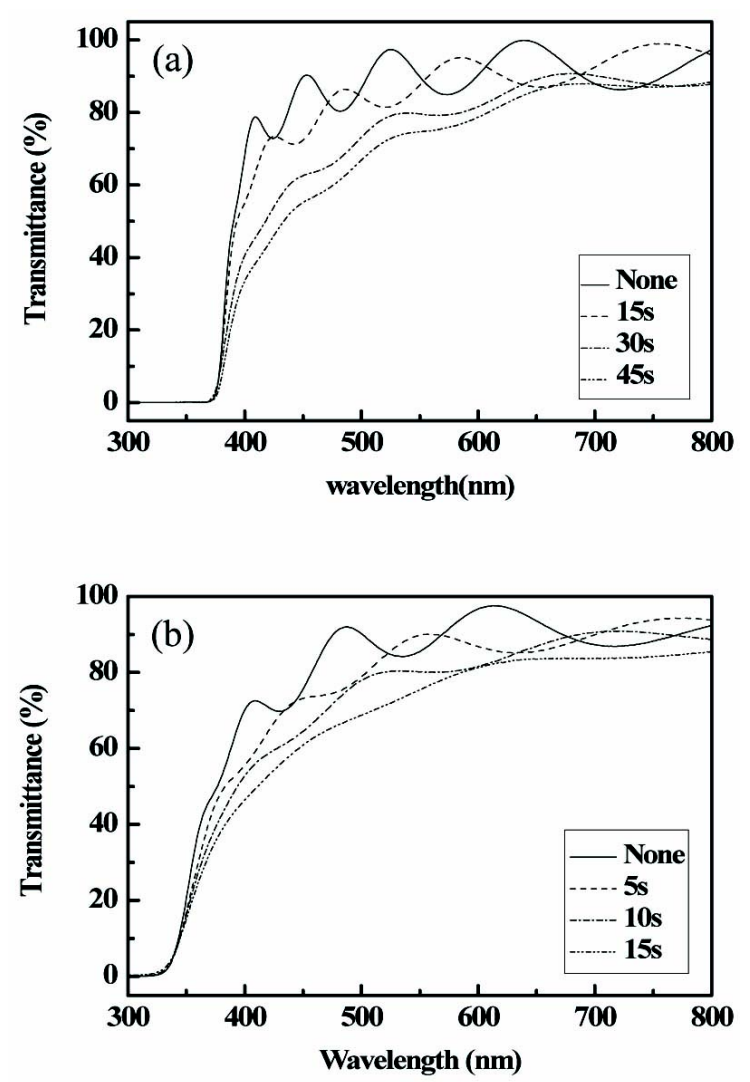

Fig. 4. Optical properties of thin films on glass substrates with etching time: (a) $\mathrm{ZnO}$, (b) AZO.

그래프에서 확인할 수 있듯이 etching 시간이 증가 함에 따라 두 박막 모두 투과율이 감소하는 것을 확 인할 수 있었다. 이는 표면의 texture structure로 인 해 박막을 통과하는 빛이 산란되어 확산 투과 성분이 증가되고, 직진 투과 성분이 감소함에 따라 이와 같 은 현상이 발생하는 것이다.

\section{4. 결 론}

$\mathrm{ZnO}$ 와 $\mathrm{Al}$-doped $\mathrm{ZnO}$ 박막의 표면형상과 박막의 전기 - 광학적 특성에 미치는 wet etching시간의 영향 을 살펴보았다.
$\mathrm{ZnO}$ 박막과 $\mathrm{AZO}$ 박막 모두 etching 시간이 증가 하면서 표면에서 texturing structure가 형성되었고, $\mathrm{RMS}$ 값은 증가하는 경향을 보였다. 또한, $\mathrm{ZnO}$ 의 경 우 etching 시간이 증가함에 따라 비저항은 약간 감 소하는 경향을 보였으나 평균적으로 $4.0 \times 10^{-3} \Omega \cdot \mathrm{cm}$ 의 낮은 비저항 값을 보였다. $\mathrm{AZO}$ 의 경우에는 etching 시간의 증가와 더불어 비저항은 $1.0 \times 10^{-3}$ $\Omega \cdot \mathrm{cm}$ 의 낮은 비저항 값을 보였다. 두 박막 모두 etching 시간이 증가함에 따라 투과율은 감소하였다. 이는 표면의 texture structure로 인해 박막을 통과하 는 빛이 산란되어 확산 투과성분이 증가되고, 직진 투과 성분이 감소함에 따라 이와 같은 현상이 발생하 는 것으로 추론된다.

\section{감사의 글}

이 논문은 2011학년도 동명대학교 교내학술연구비 지원에 의하여 연구되었음.

\section{REFERENCES}

[1] C. G. Granqvist, and A. Hultaker, Thin Solid Films, 411, 1 (2002).

[2] K. A. Sierros, N. J .morris, S. N. Kukureka, and D. R. Cairns, Wear, 267, 625 (2009).

[3] L. Raniero, I. Ferreira, A. Pimentel, A. Goncalves, P. Canhola, E. Fortunato, and R. Martins, Thin Solid Films, 511, 295 (2006).

[4] T. Minami, Thin Soloid films, 516, 5822 (2008).

[5] M. F. A. M. Hest, M. S .Dabney, J. D. Perkins, and D. S. Ginley, Thin Solid Films, 496, 70 (2006).

[6] M. Nisha, S. Anusha, A. Antony, R. Manoj, and M. K. Jayaraj, Appl. Surf. Sci., 252, 1430 (2005).

[7] T. Hitosugi, A. Ueda, S. Nakao, N. Yamada, Y. Furubayashi, Y. Hirose, T. Shimada, and T. Hasegawa, Appl. Phys. Lett., 90, 212106 (2007). 